\title{
A Study of Prognostic Factors of Chinese Patients with Gynecologic Tract Carcinosarcomas Prognosis of Gynecologic Carcinosarcomas
}

This article was published in the following Dove Press journal: Cancer Management and Research

\section{Dan Ye Hao-Ran Shen (D) Liangqing Yao}

Obstetrics and Gynecology Hospital of Fudan University, Shanghai 2000II, People's Republic of China
Correspondence: Liangqing Yao Obstetrics and Gynecology Hospital of Fudan University, Shanghai 2000II, People's Republic of China

$\mathrm{Tel} / \mathrm{Fax}+86-02 \mathrm{I}-33189900$

Email sherryye1217@I63.com
Background: Thinking of the rarity and malignancy of gynecologic tract carcinosarcomas (GTCS), the aim of the study was to investigate the possible predictors of relapse-free survival (RFS) and overall survival (OS) for GTCS patients.

Methods: We performed a retrospective cohort study of women with GTCS at our hospital between January 2009 and December 2013. We used the Kaplan-Meier method to calculate RFS and OS, and Cox regression analysis to define the survival effects of risk factors.

Results: A total of 45 GTCS patients were included in the study. The median follow-up time was 46 months. Cox regression analysis showed that lymph node metastasis was significantly associated with worse RFS (HR: 3.145; 95\%CI: $1.181-8.378 ; P=0.022$ ) and OS (HR: 4.065; 95\%CI: $1.57-10.524 ; P=0.004)$. Pelvic lymphadenectomy had a favorable RFS (HR: 0.213 ; 95\%CI: $0.057-0.796 ; P=0.021)$.

Conclusion: Lymph node metastasis significantly affected the prognosis of uterine carcinosarcoma. Pelvic lymphadenectomy could reduce the relapse rate of GTCS patients.

Keywords: pelvic lymphadenectomy, relapse-free survival, overall survival, gynecologic tract carcinosarcomas

\section{Introduction}

Gynecologic tract carcinosarcomas (GTCS), composed both of sarcomatous and of carcinomatous components of high grade, and previously known as malignant mixed Müllerian tumors. ${ }^{1,2}$ Traditionally, GTCS was regarded as a subtype of uterine sarcoma; however, its origin remained controversial. Many researchers believed it to be a type of metaplastic endometrial carcinoma with very similar clinical features to it, including symptoms of postmenopausal vaginal bleeding, aggressive behavior, and poor prognosis. ${ }^{3}$ Carcinosarcomas were also reclassified by the International Federation of Gynecology and Obstetrics (FIGO) as an aggressive type of endometrial cancer. ${ }^{4}$ GTCS typically affected postmenopausal women, rarely occurring in women $<40$ years old. ${ }^{5,6}$ The spread of GTCS was similar to that of high-grade endometrial carcinoma, and they shared similar risk factors, such as obesity, nulliparity, and estrogen use. ${ }^{3}$ It was classified as an endometrial carcinoma because of its high malignancy. ${ }^{7,8}$ The five-year survival rate of uterine carcinosarcomas was $30 \%$; in stage I, in which tumor was limited to the uterus, the fiveyear survival rate was only $50 \%{ }^{9}$ Surgery was the first-line therapy; according to the 2016 National Comprehensive Cancer Network (NCCN), ${ }^{10}$ the standard therapy 
for uterine carcinoma was surgery, including hysterectomy and bilateral salpingo oophorectomy. However, the rarity of GTCS made them account for fewer than $5 \%$ of endometrial cancer diagnoses. ${ }^{11}$ Because of its unfavorable prognosis, many researchers believed that staging surgery, even tumor reduction should be carried out, along with the adjuvant therapy, such as chemotherapy or radiotherapy or both. But there were still controversies about therapy of GTCS. In the related studies of GTCS, there were only some small, retrospective studies. Across studies, FIGO staging has long been considered as a predictor of poor prognosis. ${ }^{12}$ The purpose of this study was to identify factors in Chinese GTCS patients that are associated with the survival outcome.

\section{Materials and Methods \\ Patient Population}

This single-center, retrospective cohort study included patients diagnosed with GTCS, they underwent surgery at the Obstetrics and Gynecology Hospital of Fudan University between January 2009 and December 2013. Patients who underwent other therapies before surgery, such as chemotherapy or radiotherapy, or who also had other types of carcinoma were excluded from this study. All pathology was reviewed by the gynecologic pathologist of our hospital to confirm histology according to the 2015 World Health Organization (WHO) pathological classifications. ${ }^{13}$ The study was approved by the review board of the Obstetrics and Gynecology Hospital of Fudan University.

The patient clinical records were reviewed, and the following information was recorded: patient age; symptoms; preoperation curettage; disease stage according to the 2014 FIGO staging system for endometrial carcinoma; ${ }^{14}$ type of surgical treatment, lymph node status and follow-up data, including the recurrence time, site of focus, and date of death. For those who underwent incomplete surgical staging, stage was based on the macroscopic pathologic findings, with unevaluated areas considered negative for metastatic lesions.

\section{Statistical Analysis}

The statistical analysis was performed with SPSS 19 (IBM Corporation, Armonk, NY, USA). Descriptive statistics and comparative statistics were used for clinical characteristics, continuous or categorical variables of the cohort, respectively, the latter contains Student's $t$-test, Wilcoxon rank-sum test, chi-squared or Fisher's exact tests. Survival data were assessed using Kaplan-Meier method, log-rank test was used to distinguish hypothesis. Overall survival referred to the day the diagnosis began to the day of loss of follow-up or death; recurrence-free survival meant from the time of diagnosis until the day of relapse or death. Cox multivariate regression was used to evaluate prognostic factors, $P$-values of 0.05 or less were considered significant.

\section{Results}

A total of 45 patients with carcinosarcomas in the uterus were identified, their basic characteristics are shown in (Table 1). The median age was 57 years (range: 18-79). Thirty-two (71.1\%) cases were postmenopausal. The main reason for seeking medical advice was irregular vaginal bleeding, which occurred in 33 patients (73.3\%), followed by watery drainage, which occurred in eight patients $(17.8 \%)$, others such as abdominal distention or abdominal mass in two patients $(8.9 \%)$. Thirty-two of them had curettage before surgery, only 21 of 32 patients were diagnosed with carcinosarcoma, the remaining 11 patients were diagnosed with endometrium carcinoma.

Except for the six cases that did not undergo lymphadenectomy, the remaining 39 patients underwent complete surgical staging, including hysterectomy and bilateral salpingo oophorectomy and lymphadenectomy, of which seven of them underwent both pelvic lymphadenectomy and para-aortic lymphadenectomy. Among 39 patients who underwent complete surgical staging, nine patients were found to have nodal metastasis $(20 \%)$. According to the current 2014 FIGO staging system, 22 (48.9\%), seven (15.6\%), 13 (28.9\%), and three (6.7\%) patients had stage I, II, III, and IV disease, respectively.

A total of 39 patients underwent chemotherapy after surgery, generally a combination of platinum, ifosfamide, and paclitaxel.

The median duration of follow-up was 46 months (range: $0.5-151)$ and 18 patients (40\%) had disease recurrence. The recurrences were observed in the pelvis alone in 13 patients and in the vaginal cuff, abdominal cavity, lymph node, both vaginal cuff and lymph node, lung, and brain in one patient each.

According to the univariate Cox regression analysis of all patients, lymph node metastasis (LNM) and FIGO staging were found to have a significant impact on prognosis, both OS and RFS, drawing a survival curve with Kaplan-Meier curves $(P=0.004$ and $P=0.01, P=0.003$ and 
Table I Demographic, Clinicopathologic, Treatment and Recurrence Data

\begin{tabular}{|c|c|}
\hline Characteristics & $\begin{array}{l}\text { Gynecologic Tract } \\
\text { Carcinosarcomas Patients }(n=53)\end{array}$ \\
\hline $\begin{array}{l}\text { Age (years) } \\
\qquad \text { Median (range) }\end{array}$ & 57 (18-79) \\
\hline $\begin{array}{c}\text { Menopause status } \\
\text { Premenopausal } \\
\text { Postmenopausal }\end{array}$ & $\begin{array}{l}13(28.9) \\
32(71.1)\end{array}$ \\
\hline $\begin{array}{l}\text { Symptoms } \\
\text { Irregular bleeding } \\
\text { Vaginal drainage } \\
\text { Others } \\
\text { Preoperative diagnosis } \\
\text { Carcinosarcoma } \\
\text { Endometrium carcinoma } \\
\text { unknown }\end{array}$ & $\begin{array}{l}33(73.3) \\
8(17.8) \\
4(8.9) \\
21(46.7) \\
11(24.4) \\
9(20)\end{array}$ \\
\hline $\begin{array}{l}\text { Lymphadenectomy } \\
\text { Pelvic } \\
\text { Pelvic and para-aortic } \\
\text { Not performed }\end{array}$ & $\begin{array}{l}32(71.1) \\
7(15.6) \\
6(13.3)\end{array}$ \\
\hline $\begin{array}{l}\text { FIGO stage } \\
\text { I } \\
\text { II } \\
\text { III } \\
\text { IV }\end{array}$ & $\begin{array}{l}22(48.9) \\
7(15.6) \\
13(28.9) \\
3(6.7)\end{array}$ \\
\hline $\begin{array}{l}\text { Chemotherapy } \\
\text { Performed } \\
\text { Not performed }\end{array}$ & $\begin{array}{l}39(86.7) \\
6(13.3)\end{array}$ \\
\hline $\begin{array}{l}\text { Lymph nodes } \\
\text { Negative } \\
\text { Positive }\end{array}$ & $\begin{array}{l}36(80) \\
9(20)\end{array}$ \\
\hline $\begin{array}{l}\text { Recurrence } \\
\text { No } \\
\text { Yes }\end{array}$ & $\begin{array}{l}27(60) \\
18(40)\end{array}$ \\
\hline $\begin{array}{r}\text { Survival } \\
\text { Dead } \\
\text { Alive }\end{array}$ & $\begin{array}{l}19(42.2) \\
26(57.8)\end{array}$ \\
\hline $\begin{array}{l}\text { Follow-up time (months) } \\
\text { Median (range) }\end{array}$ & $46(0.5-|5|)$ \\
\hline
\end{tabular}

$P=0.011$, seen in Table 2, Figures 1 and 2). Lymphadenectomy was found to have a significant impact on RFS ( $P=0.02$, seen in Table 2, Figure 3). Cox regression analysis showed that only pelvic lymphadenectomy was associated with favorable RFS (HR: 0.213; 95\%CI: $0.057-0.796 ; P=0.021)$, LNM was significantly associated with worse RFS and OS (HR: 3.145; 95\%CI: 1.181-8.378; $P=0.022$ and HR: 4.065 ; 95\%CI: $1.57-10.524 ; P=0.004)$. (Table 3 ). Six of 45 patients did not undergo lymphadenectomy (Table 4). Three patients were stage IV, two patients were stage I, one patient were stage III. Except one patient who was at stage I who did not relapse, almost all of them relapsed soon after surgery, and soon died because of the relapse.

\section{Discussion}

Despite progression in cancer screening and therapies over the past few decades, not much progress has been made regarding GTCS. The best treatment protocol for GTCS was still lacking and the prognostic factors are not yet well known.

Park et al $^{15}$ also performed a retrospective study of 41 uterine CS to evaluate the effect of pelvic and para-aortic lymphadenectomy on prognosis; the patients had no obvious metastasis beyond the uterus during surgery and received complete surgical staging. After the staging procedure, nearly $7 \%$ of patients had para-aortic lymph node metastasis, but no pelvic lymph node metastasis at the same time, approximately $24-55 \%$ of patients with preoperative uterine confined CS were upstaging, and 20-38\% of upstaged patients due to pelvic and/or para aortic lymph node metastases. Therefore, the author suggested that lymph node metastasis of the uterine CS may be skipped, pelvic and para-aortic lymphadenectomy should be performed in patients with apparent early uterine CS, especially in those with myometrial invasion over $1 / 2$ or with lymphovascular space invasion (LVSI). The author proposed that, even though no obvious focus was visible beyond the uterus during surgery, upstaged pathology was possible after surgery.

One single-center retrospective study was carried out to assess the prognostic factors affecting survival of Chinese patients with GTCS. The results revealed that pelvic lymphadenectomy is significantly associated with RFS and OS, LNM is significantly associated with OS and FIGO staging is significantly associated with RFS. Of the entire cohort, 10 were diagnosed with LNM, corresponding to a rate of $18.87 \%$, the results were similar to our study. Among the 45 cases of uterine CS, 25 were classified as stage I after complete surgical staging during postoperative follow-up, three of which had metastasized beyond the uterus; one recurred a month after surgery, the earliest such recurrence. Three cases of uterine CS had no obvious LNM during surgery, but were diagnosed 
Table 2 Univariate Cox Regression Analysis for RFS and OS

\begin{tabular}{|c|c|c|c|c|}
\hline \multirow[t]{2}{*}{ Characteristics } & \multicolumn{2}{|c|}{ Recurrence-free Survival } & \multicolumn{2}{|l|}{ Overall Survival } \\
\hline & HR (95\%Cl) & $P$-value & HR $(95 \% \mathrm{Cl})$ & $P$-value \\
\hline \multicolumn{5}{|l|}{ Menopause status } \\
\hline Premenopausal & Ref & & Ref & \\
\hline Postmenopausal & $\mathrm{I} .099(0.392-3.083)$ & 0.858 & $1.143(0.411-3.176)$ & 0.798 \\
\hline \multicolumn{5}{|l|}{ lymphadenectomy } \\
\hline Not performed & Ref & & Ref & \\
\hline pelvic & $0.247(0.086-0.7 \mathrm{II})$ & 0.02 & $0.446(0.146-1.361)$ & 0.156 \\
\hline pelvic and para-aortic & $0.936(0.352-2.49)$ & 0.895 & I.898(0.744-4.842) & 0.18 \\
\hline \multicolumn{5}{|l|}{ Preoperative diagnosis } \\
\hline Carcinosarcoma & Ref & 0.872 & Ref & 0.227 \\
\hline $\begin{array}{l}\text { Endometrium carcinoma } \\
\text { unknown }\end{array}$ & $1.063(0.506-2.23 \mathrm{I})$ & & $1.56 \mathrm{I}(0.758-3.2 \mathrm{I} 5)$ & \\
\hline \multicolumn{5}{|l|}{ FIGO stage } \\
\hline 1 & Ref & 0.035 & Ref & 0.014 \\
\hline II & $0.137(0.031-0.595)$ & 0.008 & $0.104(0.024-0.45)$ & 0.002 \\
\hline III & $0.202(0.033-1.24 I)$ & 0.084 & $0.142(0.023-0.889)$ & 0.037 \\
\hline IV & $0.466(0.12-1.807)$ & 0.269 & $0.342(0.087-1.339)$ & 0.123 \\
\hline \multicolumn{5}{|l|}{ Chemotherapy } \\
\hline Not performed & Ref & & Ref & \\
\hline Performed & $0.039(0.000-13.346)$ & 0.276 & $0.039(0.00-10.766)$ & 0.258 \\
\hline \multicolumn{5}{|l|}{ Lymph nodes } \\
\hline Negative & Ref & & Ref & \\
\hline Positive & $3.534(1.359-9.236)$ & 0.01 & $4.065(1.57-10.024)$ & 0.004 \\
\hline
\end{tabular}

Abbreviations: OS, overall survival; RFS, relapse-free survival.

with it after pathology and were upstaged to stage III. free survival (PFS) and OS; deep muscularis invasion and Therefore, lymph node metastases could be found in uterine CS by pathology despite the obvious or lack of metastasis during surgery; thus, complete surgical staging is necessary even for obvious early stage uterine CS. In uterine CS, deep muscularis invasion, focus beyond the uterus, and LNM were risk factors for both progressionfocus beyond the uterus were positively related to LNM (related rate: $0.45 ; P<0.05$ ). Therefore, for those patients with one of the first two risk factors, pelvic and para-aortic lymphadenectomy may be necessary. ${ }^{16-18}$

All these precedent studies showed that lymph node dissection was important for the prognosis of
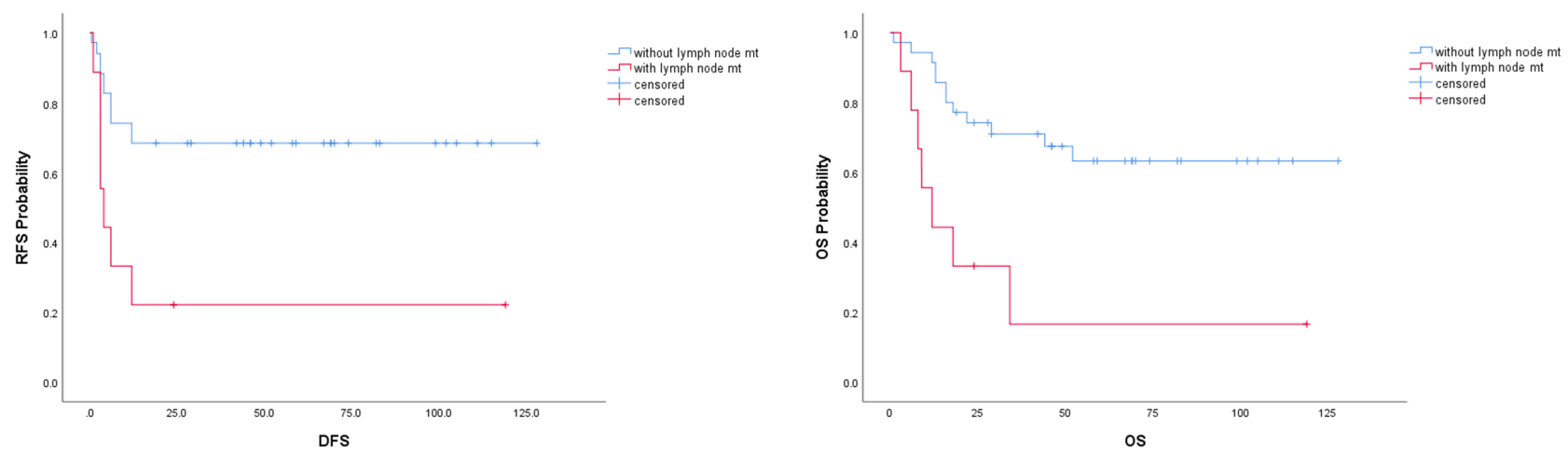

Figure I The analysis between lymph node metastasis and RFS, OS by univariate Cox regression analysis $(P=0.01$ and $P=0.004)$. 

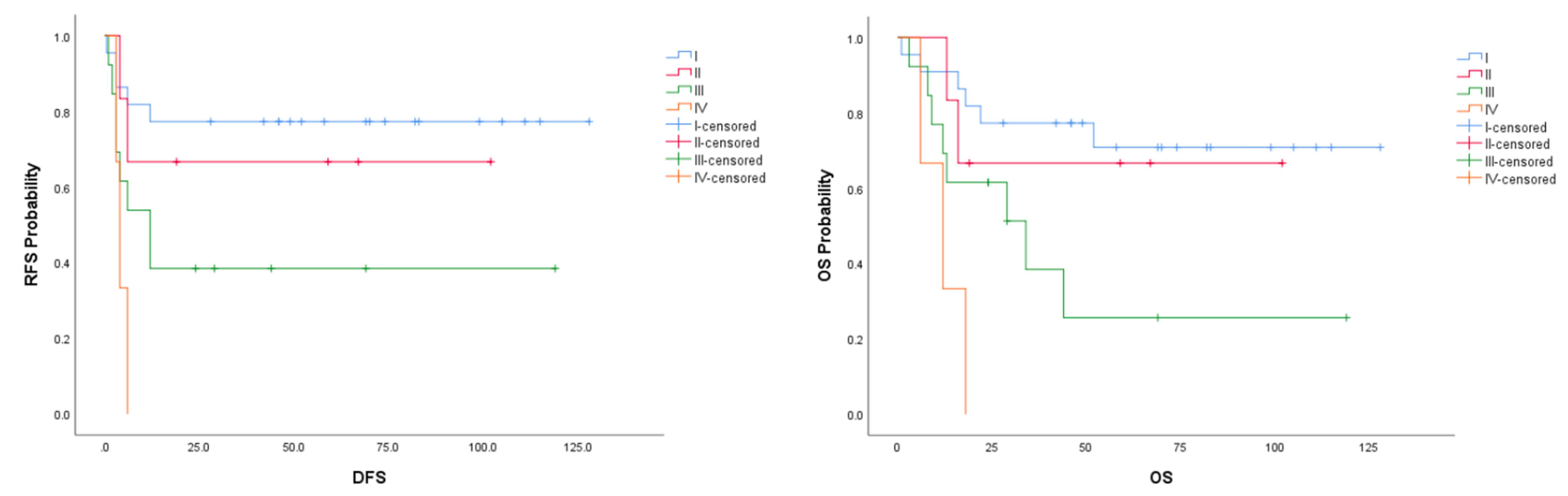

Figure 2 The analysis between stage and RFS, OS by univariate Cox regression analysis $(P=0.011$ and $P=0.003)$.
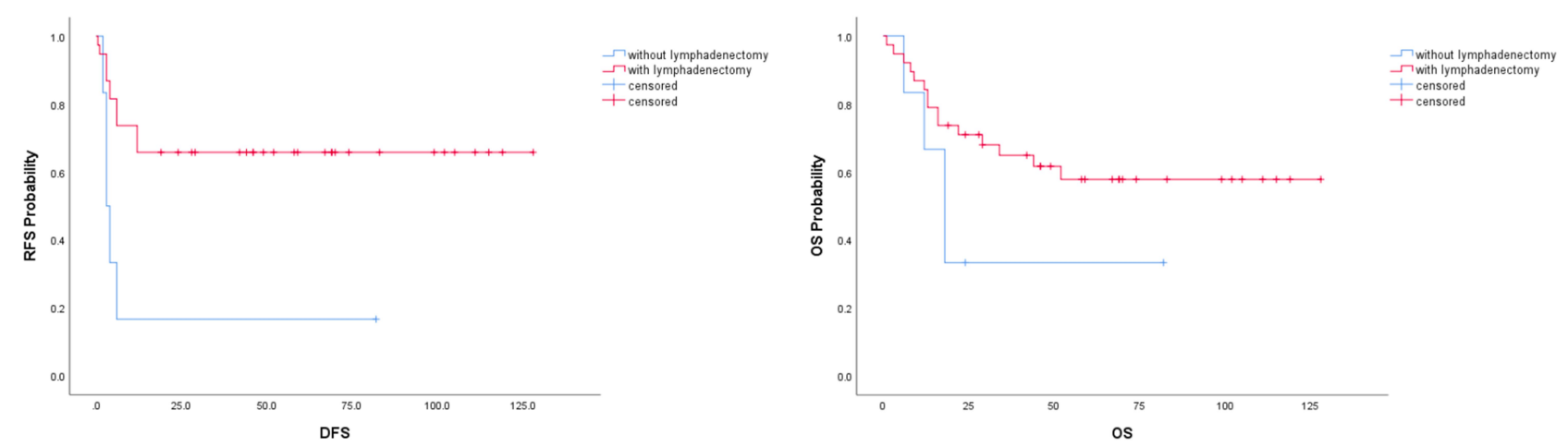

Figure 3 The analysis between lymphadenectomy and RFS, OS by univariate Cox regression analysis $(P=0.02$ and $P=0.156)$.

carcinosarcoma and should not be avoided in patients without macroscopic lymph node enlargement, as for the patients who had risk factors, such as deep muscularis infiltration, extrauterine metastatic lesions, or visible to the naked eye lymph node enlargement, lymphadenectomy was particularly important.

Table 3 Multivariate (Stepwise Variable Selection) Cox Regression Analysis for RFS and OS

\begin{tabular}{|c|c|c|c|c|}
\hline \multirow[t]{2}{*}{ Characteristics } & \multicolumn{2}{|c|}{ Recurrence-free Survival } & \multicolumn{2}{|l|}{ Overall Survival } \\
\hline & HR $(95 \% \mathrm{Cl})$ & $P$-value & HR $(95 \% \mathrm{Cl})$ & $P$-value \\
\hline \multicolumn{5}{|l|}{ Lymph nodes Mt } \\
\hline Negative & Ref & & Ref & \\
\hline Positive & $3.145(1.181-8.378)$ & 0.022 & $4.065(1.57-10.524)$ & 0.004 \\
\hline \multicolumn{5}{|l|}{ Menopause status } \\
\hline Premenopausal & Ref & & Ref & \\
\hline Postmenopausal & $0.702(0.222-2.214)$ & 0.542 & $0.776(0.25 I-2.402)$ & 0.660 \\
\hline \multicolumn{5}{|l|}{ lymphadenectomy } \\
\hline Not performed & Ref & & Ref & \\
\hline pelvic & $0.213(0.057-0.796)$ & 0.021 & $0.426(0.121-1.501)$ & 0.184 \\
\hline \multicolumn{5}{|l|}{ FIGO stage } \\
\hline 1 & Ref & 0.433 & & 0.238 \\
\hline II & $0.92(0.117-7.253)$ & 0.937 & $0.104(0.024-0.450)$ & 0.227 \\
\hline III & $1.88(0.134-26.323)$ & 0.639 & $0.142(0.023-0.889)$ & 0.984 \\
\hline IV & $2.864(0.36-22.821)$ & 0.320 & $0.342(0.087-1.339)$ & 0.824 \\
\hline
\end{tabular}

Abbreviations: Mt, metastasis; OS, overall survival; RFS, relapse-free survival. 
Table 4 Clinical Data of Six Patients without Lymphadenectomy

\begin{tabular}{|c|c|c|c|c|c|c|c|c|c|}
\hline Number & $\begin{array}{l}\text { Age } \\
\text { (Years) }\end{array}$ & Symptom & Surgical Method & Stage & Chemotherapy & Relapse & Survival & $\begin{array}{l}\text { RFS } \\
\text { (Months) }\end{array}$ & $\begin{array}{l}\text { OS } \\
\text { (Months) }\end{array}$ \\
\hline I & 45 & $\begin{array}{l}\text { Abdominal } \\
\text { distension }\end{array}$ & $\begin{array}{l}\text { TH+unilateral } \\
\text { adnexectomy }\end{array}$ & III & Yes & Yes & No & 2 & 24 \\
\hline 2 & 63 & $\begin{array}{l}\text { Abnormal } \\
\text { vaginal } \\
\text { bleeding }\end{array}$ & $\begin{array}{l}\text { TH+bilateral } \\
\text { adnexectomy+ } \\
\text { omentectomy+ appendix } \\
\text { resection }\end{array}$ & IV & Yes & Yes & No & 6 & 12 \\
\hline 3 & 73 & $\begin{array}{l}\text { Abnormal } \\
\text { vaginal } \\
\text { bleeding }\end{array}$ & $\begin{array}{l}\text { TH+bilateral } \\
\text { adnexectomy+ } \\
\text { peritoneal biopsy }\end{array}$ & IV & Yes & Yes & No & 4 & 18 \\
\hline 4 & 79 & $\begin{array}{l}\text { Abnormal } \\
\text { vaginal } \\
\text { bleeding }\end{array}$ & $\begin{array}{l}\text { TH+bilateral } \\
\text { adnexectomy }\end{array}$ & 1 & No & No & Yes & 82 & 82 \\
\hline 5 & 63 & $\begin{array}{l}\text { Abdominal } \\
\text { distension }\end{array}$ & $\begin{array}{l}\text { TH+bilateral } \\
\text { adnexectomy+ appendix } \\
\text { resection }\end{array}$ & 1 & Yes & Yes & No & 3 & 18 \\
\hline 6 & 61 & $\begin{array}{l}\text { Abnormal } \\
\text { vaginal } \\
\text { bleeding }\end{array}$ & $\begin{array}{l}\mathrm{TH}+\text { Bilateral } \\
\text { adnexectomy+ } \\
\text { omentectomy+ pelvic } \\
\text { mass resection+ PA } \\
\text { lymph-nodes biopsy }\end{array}$ & IV & Yes & Yes & No & 3 & 6 \\
\hline
\end{tabular}

Abbreviations: PA lymph nodes, para-aortic lymph nodes; $\mathrm{TH}$, total hysterectomy

However, in our study, lymphadenectomy was not significantly associated with OS in multivariate analysis, perhaps because of the small cohort size, the rarity of this malignancy, or short period of follow-up.

Regarding the biological similarities between GTCS and an endometrial cancer with a de-differentiated component rather than a sarcoma, the optimal therapy was surgery, the adjuvant therapy after surgery still needs more clinical trials.

Cantrell et al ${ }^{19}$ analyzed 52,630 cases, aimed at studying whether the adjuvant therapy, chemotherapy with or without radiation can improve the prognosis of GTCS, the results were unclear.

Artioli et $\mathrm{al}^{4}$ also explored similar questions, they reviewed five different studies about adjuvant therapy after surgery, the results showed that chemotherapy and radiotherapy had an uncertain effect, chemotherapy alone or combined with radiotherapy seemed to have a good effect on prognosis, both RFS and OS in stage III and IV GTCS.

These results above were similar to our study, because of the rarity of this type of uterine malignant tumors, more trials and deeper studies into whether chemotherapy and some other adjuvant therapies could be helpful to prognosis are still needed. ${ }^{20}$

The small number of cases and lack of long-term follow-up were the major limitations of this study. The rarity of this kind of malignancy should also be considered. Therefore, additional research to include prospective studies with large sample sizes and systematic follow-ups are urgently needed.

In conclusion, LNM was an important prognostic factor for poor OS in GTCS patients. The results in our study reveal that pelvic lymphadenectomy might have a better effect on RFS of patients with GTCS. However, future meta-analysis is urgently needed, and in the hope that deeper analysis would help us to know prognostic factors better, and also find the best management for GTCS.

\section{Conclusion}

LNM were associated with RFS and OS in GTCS patients significantly. Pelvic lymphadenectomy could reduce relapse and prolong RFS significantly. 


\section{Statement of Ethics}

This was a retrospective study, and the consent was obtained from the study participants prior to study commencement, our study was approved by the Ethics Committee of the Obstetrics and Gynecology Hospital of Fudan University, the number was No. 2016-04. Personal identifiable information was required to be anonymized. All participants were verbally informed prior to the survey, the study was not carried out until permissions to collect information and publish the study data had been obtained. Subjects have given their written informed consent.

\section{Author Contributions}

Dan Ye was responsible for collecting cases, statistics and writing the articles, Hao-Ran Shen was responsible for revising the articles and polishing the language, and Liang-Qing Yao was responsible for finalizing the articles. I would also like to thank the director of pathology Department Xian Rong Zhou for his help. All authors made a significant contribution to the work reported, whether that is in the conception, study design, execution, acquisition of data, analysis and interpretation, or in all these areas; took part in drafting, revising or critically reviewing the article; gave final approval of the version to be published; they have agreed on the journal to which the article has been submitted; and agree to be accountable for all aspects of the work.

\section{Disclosure}

The authors declare no conflicts of interest in this work.

\section{References}

1. Berton-Rigaud D, Devouassoux-Shisheboran M, Ledermann JA, et al. Gynecologic Cancer InterGroup (GCIG) consensus review for uterine and ovarian carcinosarcoma. Int $j$ Gynecological Cancer. 2014;24(9 Suppl 3):S55-60. doi:10.1097/IGC.0000000000000228

2. Harlow BL, Weiss NS, Lofton S. The epidemiology of sarcomas of the uterus. J Natl Cancer Inst. 1986;76(3):399-402.

3. Bansal N, Herzog TJ, Seshan VE, et al. Uterine carcinosarcomas and grade 3 endometrioid cancers: evidence for distinct tumor behavior. Obstet Gynecol. 2008;112(1):64-70. doi:10.1097/AOG.0b013e31817 $6157 \mathrm{c}$

4. Artioli G, Wabersich J, Ludwig K, Gardiman MP, Borgato L, Garbin F. Rare uterine cancer: carcinosarcomas. Rev Histology Treatment Critical Rev Oncol Hematol. 2015;94(1):98-104. doi:10.1016/j.critrevonc.2014. 10.013
5. Otsuka I, Takaya H, Takagi K, et al. [Carcinosarcoma of the ovary treated with paclitaxel and carboplatin chemotherapy - a report of 4 cases]. Gan to Kagaku Ryoho. 2013;40(9):1249-1253. Japanese.

6. Klash S, Stanley T, Steinman J, Kim D, Yap J, Yi S. SU-E-P-38: comparison of capri applicator HDR planning methods to meet the nccn uterine neoplasm 2.2015 guidelines. Med Phys. 2015;42 (6):3235. doi:10.1118/1.4923972

7. Pecorelli S, Benedet JL, Creasman WT, Shepherd JH. FIGO staging of gynecologic cancer. 19941997 FIGO committee on gynecologic oncology. International federation of gynecology and obstetrics. Int J Gynaecol Obstet. 1999;65(3):243-249. doi:10.1016/S00207292(99)00070-3

8. Manka I, Klauber E. [Classification, treatment and results in gynecologic cancer in the world in the years 1951-1960 (reported according to the annual Report of FIGO, vol 14, 1967)]. Ceskoslovenska' Gynekologie. 1968;33(7):537. Czech.

9. Klacko M, Babala P, Miklos P, et al. [Uterine Sarcomas - a review]. Klinicka Onkologie. 2012;25(5):340-345. Czech.

10. Koh WJ, Greer BE, Abu-Rustum NR, et al. Uterine sarcoma, version 1.2016: featured updates to the NCCN guidelines. JNCCN. 2015;13 (11):1321-1331. doi:10.6004/jnccn.2015.0162

11. Hosh M, Antar S, Nazzal A, Warda M, Gibreel A, Refky B. Uterine sarcoma: analysis of 13,089 cases based on surveillance, epidemiology, and end results database. Int $J$ Gynecol Cancer. 2016;26 (6):1098-1104. doi:10.1097/IGC.0000000000000720

12. Kurnit KC, Previs RA, Soliman PT, et al. Prognostic factors impacting survival in early stage uterine carcinosarcoma. Gynecol Oncol. 2019;152(1):31-37. doi:10.1016/j.ygyno.2018.10.034

13. Lu Z, Chen J. [Introduction of WHO classification of tumours of female reproductive organs, fourth edition]. Zhonghua Bing Li Xue Za Zhi. 2014;43(10):649-650. Chinese.

14. Hoellen F, Waldmann A, Benthin S, Hanker L, Rody A, Fischer D. The role of lymphadenectomy in uterine sarcoma: a clinical practical approach based on retrospective analysis. Anticancer Res. 2014;34 (2):985-993.

15. Park JY, Kim DY, Kim JH, Kim YM, Kim YT, Nam JH. The role of pelvic and/or para-aortic lymphadenectomy in surgical management of apparently early carcinosarcoma of uterus. Ann Surg Oncol. 2010;17(3):861-868. doi:10.1245/s10434-009-0833-6

16. Inthasorn P, Carter J, Valmadre S, Beale P, Russell P, Dalrymple C. Analysis of clinicopathologic factors in malignant mixed Mullerian tumors of the uterine corpus. Int $j$ Gynecological Cancer. 2002;12 (4):348-353. doi:10.1046/j.1525-1438.2002.01117.x

17. Manolitsas TP, Wain GV, Williams KE, Freidlander M, Hacker NF. Multimodality therapy for patients with clinical Stage I and II malignant mixed Mullerian tumors of the uterus. Cancer. 2001;91 (8):1437-1443. doi:10.1002/1097-0142(20010415)91:8<1437::AIDCNCR1150>3.0.CO;2-P

18. Yamada SD, Burger RA, Brewster WR, Anton D, Kohler MF, Monk BJ. Pathologic variables and adjuvant therapy as predictors of recurrence and survival for patients with surgically evaluated carcinosarcoma of the uterus. Cancer. 2000;88(12):2782-2786. doi:10.1002/1097-0142(20000615)88:12<2782::AID-CNCR17>3.0. $\mathrm{CO} ; 2-\mathrm{K}$

19. Cantrell LA, Blank SV, Duska LR. Uterine carcinosarcoma: A review of the literature. Gynecol Oncol. 2015;137(3):581-588. doi:10.1016/ j.ygyno.2015.03.041

20. McEachron J, Heyman T, Shanahan L, et al. Multimodality adjuvant therapy and survival outcomes in stage I-IV uterine carcinosarcoma. Int J Gynecol Cancer. 2020;30(7):1012-1017. doi:10.1136/ijgc-2020001315 


\section{Publish your work in this journal}

Cancer Management and Research is an international, peer-reviewed open access journal focusing on cancer research and the optimal use of preventative and integrated treatment interventions to achieve improved outcomes, enhanced survival and quality of life for the cancer patient.
The manuscript management system is completely online and includes a very quick and fair peer-review system, which is all easy to use. Visit http://www.dovepress.com/testimonials.php to read real quotes from published authors.

Submit your manuscript here: https://www.dovepress.com/cancer-management-and-research-journal 